\title{
Oropharyngeal Cancer pT3 TNM Finding v7
}

National Cancer Institute

\section{Source}

National Cancer Institute. Oropharyngeal Cancer pT3 TNM Finding V7. NCI Thesaurus.

Code C89004.

Oropharyngeal cancer with tumor size more than 4 centimeters in greatest dimension or extension to lingual surface of epiglottis. (from AJCC 7th Ed.) 